\title{
The Connotation and Structure of General Competences Required of Higher Vocational Students in the New Era
}

\author{
LU SUN \\ General Platform Department, Beijing Information Technology College \\ Beijing Information Technology College, 100016 \\ Beijing, People's Republic of China \\ sunl@bitc.edu.cn
}

Keywords: Higher vocational education, Quality education, General competency.

\begin{abstract}
With the social and economic development in China into a new phase, innovation-driven knowledge society comes into being, which promotes the strong demand for high-quality and high-skilled labors. Higher vocational has the mission of cultivating high-quality and high-skilled labors. Yet, What is "high-quality" and how to understand "high-quality" is a hard question. This study focus on the features and structure of the quality of a qualified labor. By analyzing the previous research achievements and combining the practices and researches we conducted in the past few years, this study analyzes the connotation and structure of general competencies and hopes to provide some references for cultivating high-quality students.
\end{abstract}

\section{Introduction}

With the social and economic development in China into a new phase and the new domestic and international situation, the Chinese government adjusts itself actively and launched the Belt and Road Initiative and hopes to play a more and more important role in the global economic system. China's economic reform and development is undergoing the transformation from the labor-intensive, resource-intensive and export-oriented industry which focuses on the quantity increase and scale development to a new connotative developing mode which is featured new technique, energy conservation and environment protection. The formation of the innovation-driven knowledge society has great impact on the competence structure of the labors. By analyzing the economic changes and labor market changes taking place in the past ten years, we found that in the process of strategical economic structure adjustment, the implementation of new-type industrialization, urbanization and innovation-driven development, the labor market underwent the great changes and showed great demand for high-level technical labor and for the popularity of higher education.

Entering the 21st century, China's vocational education stepped into the track of pluralism, modernization and internationalization. On May 2nd, 2014, based on the economic and social trend of New Normal, the Chinese government launched the Decision of the State Council on Accelerating the Development of Modern Vocational Education. It advocates that "the key and basic task of higher vocational education is moral education, the mission is serving the economic and social development, and the aim is to foster employment, meet the social public services need, and adjust to reform caused by the technical improvement and production mode transform. We will deepen the system and mechanism reform and consider the government and the market wholly and make them play the right role, accelerate the construction of modern vocational education system, deepen the integration of production and education and school-enterprise cooperation, cultivate millions of high-quality labors and technical and skilled talents, upgrade the higher vocational education creatively. For the higher vocational colleges, more emphasis should be put on the cooperation between enterprise, school and research. The higher vocational colleges should cultivate the technical and skilled talents who can serve the local economic and social development, especially serve for the technical research and product upgrade for the middle and micro enterprise” [1]. The higher vocational education in China has entered into a new era. 
On Nov. 4th, 2015, the UNESCO launched the Education 2030 Framework for Action which promotes that “ By 2030, ensure that all learners acquire knowledge and skills needed to promote sustainable development, including, among others, through education for sustainable development and sustainable lifestyles, human rights, gender equality, promotion of a culture of peace and non-violence, global citizenship and appreciation of cultural diversity and of culture's contribution to sustainable development”[2]. In this document, it also says that by 2030, ensure that all learners can acquire the knowledge and skills needed for sustainable development.

In recent years, lots of experts on vocational education and the key higher vocational colleges have begun the useful theoretical and practical innovation in the fields of talents cultivating mode. They arrive at the basic consensus that higher vocational education should focus the attention on cultivating the "technology application skill" and the "high quality" of the students. For technology application skill training, some scholars and higher vocational colleges apply the outcome-based education mode, the problem-based education mode and the process-based learning mode, etc., and form some theories and accumulate some practical experience, which proves to be effective. However, for high quality cultivation, the viewpoints are divergent. By analyzing the relevant literature, we can see that scholars have tried great effort to analyze the concept of "quality" and made some achievements. Yet, there still lack the unified explanation of "quality" and scholars tend to hold different ideas about quality education and about quality education stages. Thus, carrying out quality education subjectively is inevitable. The aim of higher vocational education is to "cultivate the high quality, high skilled talents for production, management and services. Based on the research and practice of "GPTC Cultivating Mode" (GPTC is the short form for general platform technology center) in Beijing Information Technology College, this paper discusses the quality cultivating issues in higher vocational education and hopes to provide some reference for the scholars in this filed.

\section{Concept of General Competence}

When the discussion of "what high quality means" is still heated among the scholars, a couple of HRs come from the big enterprises are discussing how to absorb and retain the high quality talents. They arrive at the consensus that the criteria of the high quality talent depends neither on the academic diplomas nor the competencies but depends on whether he is the most suitable and most qualified employee for the posts in a company [3].

If the above mentioned description about "high quality talent" represents the talent criteria made by the enterprises, what the higher vocational education should respond to this criteria? By carefully analyzing the requirements proposed by the enterprises, we can make a conclusion that for enterprises, their judgement about the high quality talent is made not only on academic diplomas and competencies but also on the adaptive capacity for the key positions.

It is not a unique instance, but has its counterpart. Since 2006, Beijing Information Technology College launched the GPTC (general platform + technical center) talent cultivation mode research. Some conclusions drawn from enterprises investigation are similar. Just as we find during the enterprises investigation, some human resources managers says that in the past years when we recruit new staff, we paid more attention to the professional ability, but now, we discover that we ignored something more important,..... the basic qualities and professional qualities of the staff members, who are the import resources of the enterprises, have a close relationship with the products quality and the image of the enterprise, ...... the professional ability is no longer the unique emphasis for us" [4].

But we cannot jump to conclusion. We should try to determine whether the criteria made by the enterprises are suitable and universal. Jiang Dayuan holds that when we set the vocational teaching objectives, we should consider not only the needs of the society but also the needs of individual development. For enterprises, the goal is how to maximize the benefits. The enterprise criteria based on the judgement of benefits maximization will sometimes conflict with public value realization and personal value realization. Thus, for "the key competencies for certain job positons" proposed and concerned by the enterprises, we should analyze them and choose them scientifically. This process 
should be one which involve social public value evaluation, enterprise value evaluation and personal value evaluation.

Some meaningful researches have been made in China and abroad. Harvard University issues General Education in a Free society in 1945 [5]. It advocated that the aim of education should be to prepare an individual to become an expert both in some particular vocation or art and in the general art of the free man and the citizen. Thus the two kinds of education once given separately to different social classes must be given together to all alike. Since no one can become an expert in all fields, everyone is compelled to trust the judgment of other people. The aim of general education may be defined as that of providing the broad critical sense by which to recognize competence in any field. That is, for general education, the aim is to cultivate the effective thinking ability, communication ability, judgement-making ability and value-recognition ability. In order to help the graduates to adapt to the 21st labor market and help them to face the challenges caused by the technology improvement, National University of Singapore set the aim of general education as expanding the intelligence of the students, helping the students to think independently, developing the critical thinking and innovation ability, promoting expression ability and writing ability [6]. In China, Peking University and Fudan University innovated the talent cultivating modes. By Yuanpei Program and Fudan School, the two universities cultivate the general abilities of the students, pass on the spirit of science and arts, cultivate the healthy personality of the students, help the students to perceive different culture and way of thinking, help the students form the habit of probing and thinking independently. Analyzing the relevant research made domestic and abroad, we can see that for knowledge area, more emphasis has been put on the even distribution in human arts, society and nature. For ability cultivation, more emphasis has been put on thinking, communication, innovation and cross-discipline. For ethnics, more emphasis has been put on world view, values and view about the world, the country and the nation.

Based on the above research, investigation and GPTC talents cultivating mode, our study group launched the special research on the "the connotation and structure of general competencies required of higher vocational students". For "the key competencies for job positons", first we make the necessary analysis and selection, and then absorb and refer to the conception of "general competencies" used in Higher National Diploma in the United Kingdom. General competencies refer to the competencies which have no direct connection with the professional ability but are necessary for personal development and social development in the modern society. Professional ability refers to the knowledge and skills required for a certain position, which is important for a qualified worker.

\section{The Structure of General}

What are the general competencies that can support personal development and social development in a modern society? This is an important question to answer. The Education 2030: Incheon Declaration and Framework for Action issued by UNESCO give us some enlightenment on the trend and aim of education. We can also get some inspiration on the researches and practices made by other scholars and in other countries and places.

In the early 1970s, the famous American psychology David McClelland and colleagues conceptualized a broad array of capabilities. McClelland and his colleagues intensified competence research on management, leadership and professional jobs (i.e., skills, self-image, traits, and motives). The research results developed a picture of how a superior performer in a job thinks, feels, and acts in his/her work setting. This became a model for how to help anyone in a job, or aspiring to one, develop their capability. It became, over the coming decades, the norm for training design, selection and promotion practices, career development and even higher education in developing people for such jobs. [7]

The Higher National Diploma program in the United Kingdom consider general competencies as the transferable abilities, which is important for an adult to develop his personality and professional ability in his career. General competencies are the basis for continuing learning because as a social person we have to face lots of changes in job choosing, promotion, job changing, etc. The Higher National Diploma program defines general competencies as the self-management and development 
ability, the cooperation and communication ability, task arrangement and problem-solving ability, mathematical ability, technological ability, design and innovation ability. [8]

In order to cope with the dramatic change of the society and the fierce competition caused by globalization, Curriculum Development Council of Hong Kong issued the learning to learn - the way forward in curriculum development. In this document, the concept of "common competency" was put forward. Common competence is the basis for learning. By learning different subjects and knowledge of different domain, we can cultivate the common competency. These competencies can be transferred to other learning and study. Nine common competencies are list in this document, that is, cooperation ability, communication ability, innovation ability, critical thinking ability, information ability, mathematical ability, problem-solving ability, self-management ability, research ability. [9]

By analyzing the "common competencies" put forward by Hong Kong Curriculum Development Council, the "general competencies" by Higher National Diploma program in United Kingdom and the "job competence model" put forward by David McClelland and colleagues, we can see that they share high similarities. All of them put great emphasis on how to help the sustainable career development and how to improve job qualification in this quickly changing world. In fact, in this quickly changing world, people tend to change jobs frequently, people cannot live on one skill for the whole life and we need to learn continually. Thus, learning to learn is an important part of general competencies.

When we carry out the research on general competence model, we base the research on the social and economic background of the knowledge economy and high-tech economy, and we choose the typical position from information industry, production industry, cultural and creative industry. By investigating the enterprises, interviewing the graduates, referring to the relevant literature, argumentation by the experts, absorb the experiences domestic and abroad, analyzing the positions taken by the graduates of our school, we form the following general competence structure.

Traits: righteous, honest, responsible, empathetic, introvert, professional, etc.

Motives: positive, desire for success, persistent, abiding by the rules, etc.

Self-image: confident, self-respect, independent value judgement, emotion management, healthy lifestyle, flexibility, etc.

Social communication: interpersonal communication, team work cooperation, intercultural competence, good listener, customer-oriented, and establish relationship, etc.

Problem-solving: information collection, automotive learning, deductive thought, inductive thought, judgement and reasoning, analyzing ability, critical thinking, innovation ability.

Management ability: decision-making ability, power of influence, cultivating other people, motivating the group members, plan-making ability, coordinate ability, implementation ability, security awareness, quality awareness, environment-protection awareness, etc.

Are all these competencies can be acquired by education or training? Now let's refer back to the Iceberg Model made by David McClelland. According to him, the Job Competence Model consists of six components, that is, skills, knowledge, values, self-image, traits and motives. They are arranged in a hierarchy. Among the six components, skills and knowledge (above water) are visible, values, self-image, traits and motives (which remains beneath the surface and in the deep bottom of the sea) are hidden. It is relatively easy to change the knowledge and skill structure by training and education; self-image, such as attitude, values and confidence can be changed by training, but it is difficult than changing the knowledge and skill structures. The motives and traits are almost impossible to train and develop [10].

The above mentioned six competencies are related to each other. The six competencies develop orderly. The latter competence is based on the development of the former competency. Whether these competencies can be trained or not differs a lot. Usually, the competencies at the upper layer of the hierarchy are easily changed and the competencies at the bottom of the hierarchy are difficult to intervene.

In addition, during the process of general competencies model research, most of the interviewees chosen are people who have working experiences. Thus, among the professional abilities and general competencies, some are required before the employee begins his career, these competencies are 
called basic competencies; some are developed and accumulated during the career, these competencies are called developing competencies. Basic competencies are necessary for an employee to acquire a job and developing competencies are useful for the promotion of an employee.

Based on the above analysis, when we cultivate the general competencies of the students, we should put the emphasis on the basic competencies, while the developing competencies are developed during the long career. Thus, by deduction and induction and by using Enterprises Culture Discussion method and Key Behavioral Event Interview method, we define the qualities and competencies required for enterprise development and personal development. These qualities and competencies include: emotion management, citizenship awareness, interpersonal communication, information collection and management, tools using, automotive learning, language ability, logic thinking, dialectical thinking, critical thinking, innovation ability, intercultural awareness, adaptability, etc. The structure of general competence model are listed in the following table 1.

Table 1 The Structure of General Competence Model

\begin{tabular}{|l|l|}
\hline The General Competence Area & Key Testing Point \\
\hline Self-image & $\begin{array}{l}\text { emotion management } \\
\text { citizenship awareness }\end{array}$ \\
\hline Communication and Cooperation & $\begin{array}{l}\text { communication } \\
\text { cooperation }\end{array}$ \\
\hline Problem-solving & $\begin{array}{l}\text { tools using } \\
\text { automotive learning }\end{array}$ \\
\hline Information Management & $\begin{array}{l}\text { language ability } \\
\text { information management }\end{array}$ \\
\hline Thinking and Judging & $\begin{array}{l}\text { logic thinking } \\
\text { critical thinking }\end{array}$ \\
\hline International Outlook & $\begin{array}{l}\text { intercultural awareness } \\
\text { adaptability }\end{array}$ \\
\hline Innovation and Development & $\begin{array}{l}\text { critical thinking } \\
\text { innovation ability }\end{array}$ \\
\hline
\end{tabular}

\section{Summary}

To cultivate the general competencies of the students is a complex work. By analyzing the competence structure required of higher vocational education and decoding the connotation of the competencies, we can carry out the general competence cultivation more specifically, and promote the development of the competence structure of the students. We hope that our efforts can recommend a method for general competence cultivation of the students.

\section{References}

[1] Decision of the State Council on Accelerating the Development of Modern Vocational Education, Information on www.scio.gov.cn (in Chinese).

[2] Information on https://en.unesco.org/themes/education

[3] Information on http://www.bosshr.com/shownews_3565.html (in Chinese)

[4] Beijing Information Technology College, Basic Abilities and Vocational Qualities Training and Assessment Report for Higher Vocational Education (2010) (in Chinese).

[5] Harvard Committee, General Education in a Free Society, Harvard University Press, Cambridge, 1950.

[6] Chan A. H. P, A New General Education Reform and Its Reflections at National University of Singapore, in: Gan Yang, Sun Xiangchen, General Education Review, Fudan Press, Shanghai, 2016 (in Chinese).

[7] Information on https://en.wikipedia.org/wiki/David_McClelland 
[8] Li Xingzhi, The Competence-based Vocational Education Mode - the General Competence Cultivation in BTEC, Chinese Vocational and Technical Education, J. 27(2003):13-14 (in Chinese).

[9] Hong Kong Curriculum Development Committee, Learning to Learn - the Way Forward in Curriculum Development (2001) (in Chinese).

[10] Information on http://baike.baidu.com/view/356714.htm 